\title{
Research on the English Cross-Cultural Communication Skills from the Perspectives of Differences in Chinese and Western Thinking
}

\author{
Jing Yang \\ School Of Foreign Languages,Zhengzhou University Of Industrial Technology, \\ Zhengzhou, Henan, 451100 China
}

\begin{abstract}
In this paper, we conduct research on the English cross-cultural communication skills from the perspectives of differences in Chinese and western thinking. According to the pragmatic about the context and the speech act theory, language communication in the discourse meaning varies with the context. So in cross-cultural communication activity, we must according to specific communicative context, adjust the understanding of discourse, adjust their own words to make it right, decent, can we properly adjust communication mutual relations and the behavior of the coordination between the communicator, eventually successful communication. We believe that before explore ways for the cultivation of the intercultural communication ability, the inevitable problem that nots allow to ignore is the expurgation of intercultural communication ability. Therefore, our research integrates the other perspectives to help propose the novel methodology on the issues that is meaningful.
\end{abstract}

Keywords- Cross-Cultural, Communication Skills, Chinese and Western, Thinking Pattern.

\section{Introduction}

Cross-cultural thinking covers the analysis of cultural phenomenon, comprehensive, comparison and generalization ability. We will be summed up as cultural understanding ability and analysis ability. Cultural comprehension refers to understand the differences in human communication behavior under different cultural background, and seek to produce difference cultural root of ability; Cultural analysis ability is compared to native culture and alien culture, summarized similarities and differences. The cultivation of thinking ability is conducive to our general understanding of the cultural differences in the cross-cultural communication that solve cultural conflict to achieve effective communication.

According to the literature review, we can list the main research direction of the cross-cultural communication as the follows. (1) The research of the verbal behavior culture characteristics. On the cultural features of speech act is another important topic in the study of intercultural communication. Culture has a distinct personality and the different cultures will naturally have differences between the cultural differences reflected in the language will be the language differences. (2) The research of the nonverbal communication. Nonverbal communication is the language to convey information in the communication process, these nonverbal languages including voice tone, eye contact, body contact, facial expressions, space distance, etc. (3) Cultural values of the cultural dimensions theory research. Theory of cultural dimensions is one of the most influential in the cross-cultural theory and the study identified to distinguish different national culture of four dimensions: individualism and collectivism, power distance, uncertainty avoidance and uncertainty tolerance, masculine and feminine [1-2].

Pragmatics theory is that to be successful communication, and in addition to master the language structure, the two communicating parties must also master the pragmatic rules, know how to contact the context to accurately understand literal meaning and implicit meaning, in order to use language appropriately, with accurately express ideas. The theory with particular emphasis on the context of dynamic adjustment of word meaning is thinking that the meaning of words can't out of context, the same 
word may have different meaning in different context, if the isolated, static understanding of the conversational implicature as judgment is likely to lead to communication misunderstanding and even make communication obstructed that will cause serious concern.

Global awareness and the cultural adjustment, knowledge and communication practice constitute cross-cultural communicative competence, four are intertwined, be short of one cannot. The lack of any a kind of ability will influence the realization of the cross-cultural communicative competence. Exist at same time, four hierarchies: global consciousness is the most basic ability in cross-cultural communication ability while without cross-cultural consciousness and cultural differences between sensitivity and intellect to let alone the cultural adaptation and learning and mastering of knowledge.

\section{Ten Strategies for Effective Cross-Cultural Communication}

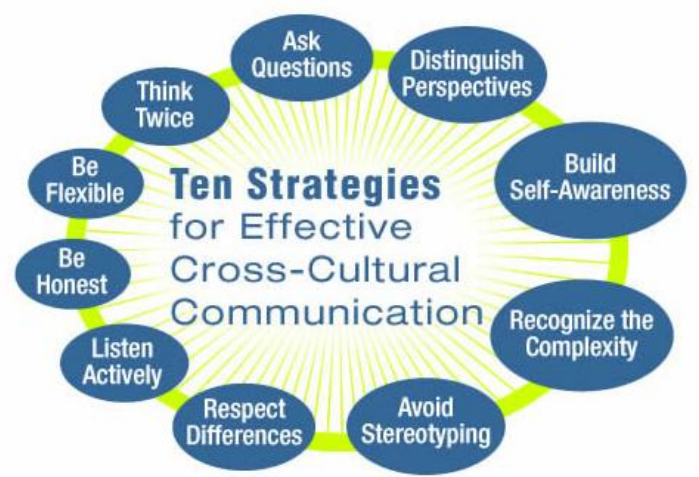

Figure 1. The Tips for Cross-Cultural Communication

In this paper, we conduct research on the English cross-cultural communication skills from the perspectives of differences in Chinese and the western thinking. In the process of the cross-cultural communication, the speaker will be an information passed on through verbal or nonverbal ways to obedient, obedient people accepted the said information and in the same way to pass information to accept and understand. But whatever the communication, we can put the study of communication, the verbal communication and nonverbal communication level because of interpersonal communication is through the two ways. In the later sections, we will propose our novel methodology.

\section{Our Proposed Methodology}

The Chinese and Western Thinking Features. Human thinking from different angles, different side to observe and reflect the objective world, also analyzes the objective world and comprehensive will be a people for a long time understanding of the reality into habit and experience, with the help of the language form, and gives thoughts in a certain way, it formed a unique mode of thinking by the nation, way of thinking is a bridge to communicate culture and language [3-4].

Culture and philosophy are inseparable, national culture and philosophy to form of thinking and language expression to extremely profound influence as language is the carrier of thinking. People's language expression is controlled by the way of thinking. Not study language not thinking, and the thinking not study philosophy of every nation can't deep. Differences in Chinese and western way of thinking for many reasons, the most important reason is the difference between the two kinds of the culture philosophy. Way of thinking is product of history as different historical times have different ways of thinking. Every way of thinking reflects the era of society and culture, reflects the degree of social productivity and science development of the times, knowledge level and practice methods. The differences of the Chinese and western thinking features can be summarized as follows.

$>$ The dialectical unification of Chinese thought and western polar opposite thinking. Chinese and western classical philosophy of dialectics, in opposition to explain the development and the changes of things, but more stressed the unification of Chinese traditional 
philosophy even opposing both sides mutual penetration and mutual conversion and unified in a whole. Angle of viewing the situation is different, each in the Chinese and western in communication under the influence of their mindset and cause the Chinese often think westerners too arrogant, while westerners think Chinese attitude is not clear with a lot of disputes and misunderstandings.

The image of Chinese perceptual thinking and the western logic and rational thinking. Image thinking is with the store some representation in the mind thinking, namely the imagination. Logical thinking, also known as abstract thinking, its characteristic is the abstract concept, the judgment and reasoning, as the basic form of thinking, to the analysis, synthesis, comparison, abstract, generalization and concretization as basic process of thinking, so as to reveal the essential characteristics of things and regularity.

Chinese comprehensive thinking and analytical thinking of western people. Chinese thinking tends to be comprehensive, so always preferred whole, each part is linked to the organic as the whole. While the western analytical thinking is part of the priority, the study on precision of each part. Comprehensive thinking combines various parts of the object, as a whole and the analytical thinking is a complete object is decomposed into components.

Forms and characteristics of mode of thinking are not simple, but have a certain mode of thinking activity of life. Any thinking activity is the unity of logic and intuition, and heart enlightenment. On the one hand, thinking is a logical activity, produce different concept of logic rules and reflect on their relations, and thus to construct a link together in a logical relationship between the basic concept of knowledge system. But on the other hand, it is a direct manifestation of thinking activities subject in this show directly with his appearance [5].
The
English
Communication

Characteristics. Training the students' ability to use the language communication is the main purpose of college English teaching is in the whole teaching process, the communicative English as the teaching goal, around the communication content and purpose as the core through the communication activities to cultivate the college students' English communicative ability. Due to the nature of the language is communication, communication function is the most basic function of language, therefore, we must learn to use English to English language acquisition.
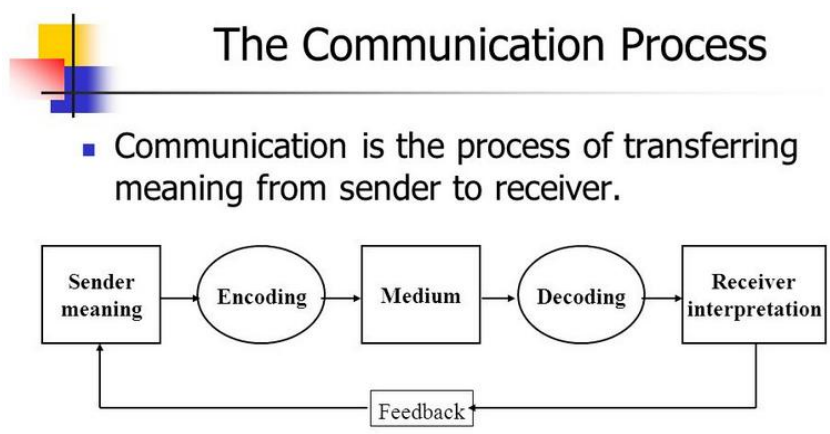

The Communication Model

Figure 2. The General Communication Procedures

The core of communicative language teaching is to improve students' communicative competence, and an important means of communication strategy is to improve the communicative competence. Communication strategy refers to language learners to overcome because of language communication barriers caused by the limited resources and skills. Accordingly, the corresponding theories could be categorized as the follows. (1) PM's and swain's theory of the communicative competence. PM's and swain's theory of communicative competence belong to the category of applied linguistics, it explain and guide the second language or the foreign language teaching and 
testing. Their theories have very specific instruction language teaching and general language testing. (2) Bachmann theory about the communicative language ability. On the basis of summarizing the predecessors' various theories, according to their own empirical research at the same time, the American scholar the Bachmann put forward his theory of the communicative language ability. He thought the communicative language ability by the language ability strategy ability and psychological physiological mechanism of the three parts, relatively speaking, Bachmann, than the PM's theory of communicative language ability and swain's theory of communicative competence more systematic, more comprehensive and more easily put into practice. (3) James' theory about communication skills. American social linguist, represented by Chomsky's linguistic theory that he thinks that a man of learning a language can not only identify whether the sentence grammatical rules and create a grammatical rules of the sentence but should also know how to use language properly, namely different time in different occasions for different objects using the different corresponding languages and theoretical perspectives [6-7].

\section{The English Cross-Cultural}

Communication Skills. English communication skill is a practical problem, must go through a lot of language practice to accumulate rich experience. Communication is inseparable from the language environment, English teachers should improve the occasion, education students at universities and the colleges in using English corner, English club, and a variety of forms, such as English speech contest, extracurricular activities, more exposure to English, the communicate with foreign teachers, more better to cultivate cross-cultural awareness to improve the ability of the cross-cultural communication [8-9].

To overcome the phenomenon of culture shock is a process of gradually, because different people have different quality of will and influence, the degree of culture shock can also vary. But, one thing is common, that is before contact cross-cultural environment whether preparation is sufficient to aspects of the language culture. If prior to the understand more, and keep a good state of mind to cope with the situation, in the process of adjustment will be more relaxed. Cross-cultural communication ability by global consciousness system, the cultural adjustment ability, knowledge, ability and communicative competence system together, they are intertwined, inseparable, constitute the basic framework of the cross-cultural communicative competence and the subsystem under each system contains the various factors of the ability to cross-cultural communication, which is closely related to the foreign language teaching. Language teaching is the center of the foreign language teaching task. Therefore, we can be in listening, speaking, reading, writing and translating of the five basic language skills training as the consciousness cultivation, culture and the communication strategy training "carrier" through analysis, purposeful questions set, role play to cultivate cross-cultural awareness raising, the accumulation of cultural knowledge and the development of cultural adjustment ability. As the reference, we illustrate the cross-cultural communication architecture in the following figure three.

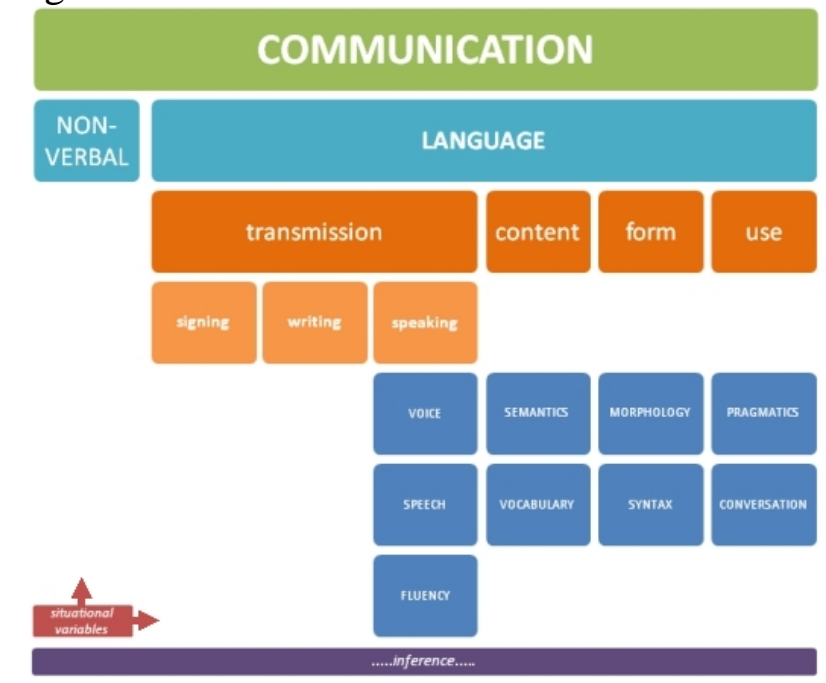

Figure 3. The Cross-Cultural Communication Architecture Demonstration 


\section{Conclusion}

In this paper, we conduct research on English cross-cultural communication skills from perspectives of differences in Chinese and western thinking. In communication, the communicator should not only obey the rules of the language structure, to obey the rules of the language usage, according to the specific circumstances, in the context of the changes in the do flexible adaptations, positive with the development of the context. In the process of the cross-cultural communication, context can help the recipient to predict whether can understand the meaning of the want to express, the recipient can help known language information and new information that move to make communicative context of the development of positive synergy, so as to achieve the real intention of communication. Discussed in this paper, in the perspective of cross-cultural communication context of the definition, classification, characteristics and its pragmatic value to let everybody to the cross-cultural communication under the perspective of context has a more comprehensive understanding more deeply and at the same time, we should also establish context awareness to constantly improve contextual analysis ability, effectively apply the context theory to practice and finally successfully achieve intercultural communication. In the later research, we will combine more theoretical review to enhance the current result.

\section{References}

[1] Knapp, Karlfried. "English as an international lingua franca and the teaching of intercultural communication." Journal of English as a Lingua Franca 4.1 (2015): 173.

[2] Shishavan, Homa Babai, and Farzad Sharifian. "The refusal speech act in a cross-cultural perspective: A study of Iranian English-language learners and
Anglo-Australian speakers." Language \& Communication 47 (2016): 75-88.

[3] Exley, Beryl E., and Kathy A. Mills. "Parsing the Australian Curriculum English: Grammar, multimodality and cross-cultural texts." Australian Journal of Language and Literacy 35.2 (2012): 192-205.

[4] Whittaker, Andrea, and Heng Leng Chee. "Perceptions of an 'international hospital'in Thailand by medical travel patients: Cross-cultural tensions in a transnational space." Social Science \& Medicine 124 (2015): 290-297.

[5] Bozrm, Michel, and Osmo Kontula. "Sexual initiation and gender in Europe: A cross-cultural analysis of trends in the twentieth century." Sexual behaviour and HIV/AIDS in Europe: comparisons of national surveys (2014): 37.

[6] Ruiz-Mafe, Carla, et al. "Key drivers of consumer purchase of airline tickets: A cross-cultural analysis." Journal of Air Transport Management 27 (2013): 11-14.

[7] Choi, Jaeyoung, et al. "Understanding the language, the culture, and the experience: translation in cross-cultural research." International Journal of Qualitative Methods 11.5 (2012): 652-665.

[8] Sun, Xiaoyun, Yuzhang Wu, and Bing Ni. "Interdisciplinary strategy to train graduate students in English communication for international academic conferences." Medical teacher 36.2 (2014): 180-181.

[9] Bücker, Joost JLE, et al. "The impact of cultural intelligence on communication effectiveness, job satisfaction and anxiety for Chinese host country managers working for foreign multinationals." The International Journal of Human Resource Management 25.14 (2014): 2068-2087. 